\title{
Wellness in pediatric radiology: lessons learned in a time of pandemic
}

\author{
Rama S. Ayyala ${ }^{1}$ (D) $\cdot$ Kimberly A. Garver ${ }^{2} \cdot$ Michael J. Callahan $^{3}$
}

Received: 13 April 2020 / Revised: 13 April 2020 / Accepted: 26 April 2020 / Published online: 14 May 2020

(C) Springer-Verlag GmbH Germany, part of Springer Nature 2020

The medical community is engaged in the COVID-19 pandemic, which has created unprecedented challenges for health care systems across the world, imposing new and previously unmatched levels of stress and anxiety for patients, families and health care workers. Stress, burnout and wellness among physicians, and specifically radiologists, has been a popular topic recently; however the events of the last few weeks have and will continue to change the discussion. It is important that we acknowledge potential new obstacles that have been identified but also recognize the lessons learned by being forced to address and cope with the issues of the pandemic.

Drivers of stress and burnout for radiologists have changed dramatically in the last month because of the COVID-19 pandemic. In the past, common causes of stress and burnout have included increasing clinical volumes, increasing complexity and acuity of cases, conflicting demands of research and teaching, struggles with work-life balance, and feeling like a $\operatorname{cog}$ in the wheel. Ironically, in the last few weeks, many of these perceived problems have been replaced by a much different set of challenges - the existential question of personal survival, the possibility of lack of personal protective equipment to safeguard oneself at work, the call to action for clinical skills that might have been dormant for decades, and the anxiety regarding the long-term psychological and economic impact on our families and communities. Along with other

Rama S. Ayyala

rayyala@gmail.com

1 Department of Diagnostic Imaging,

Rhode Island Hospital - Hasbro Children's Hospital,

Warren Alpert Medical School of Brown University,

593 Eddy St., Providence, RI 02903, USA

2 Department of Radiology, Brighton Center for Specialty Care, University of Michigan, Brighton, MI, USA

3 Department of Radiology, Boston Children's Hospital, Boston, MA, USA medical specialties, pediatric radiology departments are tasked with addressing these myriad issues that were previously unfathomable. However, these processes have shed light upon how pediatric radiology departments/institutions are coming together to navigate through this difficult time together.

We are facing many new challenges today, adding to previously identified stresses in pediatric radiology. Because of state and federal physical distancing guidelines and diminishing outpatient imaging volumes, fewer pediatric radiologists are required to physically work in the radiology department. This has led to more pediatric radiologists working remotely from personal offices or home and, in some cases, radiologists being repurposed to other clinical duties. Although decisions regarding physical distancing were made in the interest of public safety, it unfortunately has decreased regular interactions with patients, families and clinical colleagues, which is one of the most fulfilling parts of our jobs. At the same time, pediatric radiology departments are facing lower examination volumes, creating an uncertain financial outlook for individuals, practices and departments. During times of stress and anxiety, reaching out to others for support is one of the most recognized ways to provide relief and maintain psychological well-being. A major stressor being imposed on many by our current situation is the sudden isolation from family, friends, colleagues and trainees. In addition, some are struggling with their moral distress of feeling relatively helpless in a situation that primarily affects adults along with the possibility of not having the medical skills to help the suffering patients and our more front-line colleagues.

Despite these pressing challenges, we have been amazed by the resilience, optimism and innovation that have been exhibited by both our clinical and non-clinical colleagues. This humanitarian crisis has increased our sense of collective purpose as healers to the people we serve. It has emphasized the vital roles of all staff in a pediatric radiology department - especially our technologists, mid-level providers, nurses, office and 
front desk personnel staff, patient experience representatives, and trainees. It is often only during the most grim and challenging times when we appreciate how teamwork is the foundation of pediatric radiology. Providing optimal pediatric patient care truly takes a village.

Although we might all be feeling more physically and emotionally distant, we are embracing technology to help us connect with colleagues from our institutions and throughout the world. This convenience of technology in our homes has allowed us to maintain social contact, allowing for more connections and conversations than we would typically have time for in the department or across the community. At our respective institutions, substantially more individuals are able to participate in clinical and teaching conferences on a daily basis, which has been an unexpected positive outcome of the pandemic. Utilizing the virtual platforms for teaching has sparked multi-institutional collaborations to provide content and allow various people to share their expertise. Some institutions are also using this time to invest in developing virtual teaching opportunities for technologists as well as trainees. These new virtual methods have not only allowed us to reconnect with our colleagues in our departments/institutions, but they have also led us to lean on colleagues around the country and world. More than ever, we have been able to rely on one another for advice, support and the sharing of knowledge and ideas of how to cope with these challenges.
This pandemic will change our lives and the face of medicine forever, in a yet-to-be-determined way. However, this crisis has serendipitously renewed our sense of purpose and will likely bring the international pediatric radiology community closer together. For many of us, these simple connections might uncover a clearer appreciation of our jobs, something many of us might have lost sight of recently, or previously took for granted. Our departments have been strengthened by the knowledge and recognition that we need one another to provide the best care possible for our patients, highlighting the importance of all members of the department in achieving these goals. Our teams have come together to create and leverage new tools for working, collaboration and education. This is a challenging and uncertain time for us all, but we are being reminded of our purpose and the virtues of a career in pediatric radiology, and together we will prevail and be stronger and more compassionate clinicians.

\section{Compliance with ethical standards}

Conflicts of interest None

Publisher's note Springer Nature remains neutral with regard to jurisdictional claims in published maps and institutional affiliations. 